\title{
A Study of Subtitle Translation From the Perspective of the Skopos Theory-Taking The Vampire Diaries as a Case
}

\author{
MA Ying \\ China University of Geosciences, Wuhan, China
}

\begin{abstract}
With the development of the mass media technology, foreign film and television works, especially U.S. TV drama, have gained a firm footing in the Chinese market place. Then, as the era advances, Chinese people's material living has been improved and they begin to pursue the spiritual values. As a result, the rise of U.S. TV drama makes the translation of films with original sounds and subtitles get more recognition and welcome. As an effective form of intercultural communication, subtitle translation is a purposeful behavior and it aims to convey the needed information to audiences for a better understanding and appreciating of the film effectively and accurately. Nevertheless, the subtitle translation in China is still in the early stages and its translation system will become better in the further development. This article takes The Vampire Diaries as a case from the perspective of the Skopos Theory, analyzes the features and purposes of the subtitle translation, and then finds out the proper strategies of subtitle translation. Hopefully, this thesis can make a contribution for the future research and practice in dealing with subtitle translation.
\end{abstract}

Keywords: U.S. TV drama, subtitle translation, the Skopos Theory, The Vampire Diaries

\section{Introduction}

With the deepening of reform and opening up, people's living standard has risen considerably. After China accedes to WTO, foreign film and television works take the opportunity to open up China market and resonate with Chinese customers. The success of U.S. TV drama has also marked the progress of cultural exchanges between China and foreign countries. Meanwhile, it seems to be an eternal topic to talk about youth, so the artistic and horror vampire TV drama attracts many young people. Therefore, the subtitle translation, a newly arisen translation field, has become more and more important.

Thanks to the limitation of technology, Chinese subtitle translators cannot make subtitle translation accurately and effectively. After Hans Vermeer (1989) put forward the Skopos Theory, translators could find a proper and unified method to do subtitle translation. The significance of this thesis is to make scholars who are studying subtitle translation pay more attention to the theory so that the quality of the subtitle translation will be improved. This thesis is an attempt to analyze subtitle translation from the perspective of the Skopos Theory to explore proper methods in subtitle translation.

MA Ying, M.A. candidate, School of Foreign Language, China University of Geosciences, China. 


\section{Skopos Theory}

In the 1970s, a German skopos school originator called Hans J. Vermeer put forward the Skopos Theory in his paper Framework for a General Translation Theory to express the translation purposes. The Skopos Theory holds that the purpose of translation is the primary consideration and then translators choose the translating method according to the translation purpose instead of making conclusion whether using domestication or dissimilation. Compared with traditional equivalence-based translation theory, the Skopos Theory lays less stress on the equivalence between target text and source text and it does not care whether the target text is perfect or not. It emphasizes that the target text should be made on condition of analyzing the source text previously.

There are three rules in the Skopos Theory for translators to obey, which are Skopos rule, Coherence rule, and Fidelity rule. As Vermeer explains, the purpose of translation means translating process, translating result, and translation method. Coherence rule means that translators should consider the education background and actual state of target acceptors. The fidelity rule claims that the target text which translated from source text should be loyal to the source text.

\section{The Application of Skopos Theory in the Subtitles Translation of The Vampire Diaries}

According to the Skopos Theory, translators should figure out the main purpose of the target text and translate the subtitle from the perspective of the Skopos Theory.

\section{Domesticating Strategy}

Domesticating method is a way to decrease foreign look and fully consider the purpose of readers. As regards The Vampire Diaries, target-language audiences and source-language audiences are form different countries, so they are in the different cultural situations and have different thinking modes, language habits, individual experiences, and education levels. The translators should fully adopt the domesticating method and consider these differences to make the target-language audiences understand the subtitle translation easily.

Example (1) Viki: Like you care. 别假惺惺了。

The translator considers Chinese expression types and adopts the domesticating method. Besides, the subtitle translation is in keeping with the Viki's mood, because she is disgusted with Taylor and the translation can express the discontent and indignation of her.

\section{Colloquial Translation}

Most of the dialogues in TV series are informal and filled with colloquialism. Besides, the TV works are forms of popular entertainment. Thus, colloquialism is a common feature that must be accurately represented.

Example (2) She tries to kill Jenna, we can’t just forget it.

$$
\text { 我们不能就这么算了。 }
$$

The translator adopts the domesticating tragedy and translates it into “我们不能就这么算了”. It matches English expressions and becomes very easy and familiar for the target audiences to understand the meanings naturally and acceptably.

\section{Four-Character Phrases}

The target audiences of The Vampire Diaries are young people and they are fond of speaking catchwords. 
Besides, Chinese people are in favor of four-character phrases, which make their talks more forceful and sometimes more academic. Four-character phrases can show the cultural knowledge and conservation of translators, and have a flowing sense about it and impress the audience deeply.

Example (3) Viki: Yeah, I mean. I'm the screwed-up one.

我命运多多。

The conversation happens when Viki grumbles to Damon about her miserable fate. If we translate it into “是 的, 我的意思是我是一个糟糕的人”, which may make us feel that Viki has done something wrong to make her fate bad. So it will be better to translate the sentence into “我命运多多”.

\section{Amplification}

Some conversations in The Vampire Diaries are too simple and short, which cannot be understood easily by target audiences and they may spend long time in digesting this in silence. So translators should transfer the source language into a direct one and convey the meaning behind a behavior.

Example (4) Yes, we can. If it keeps us safe. Obviously, there are some sentence elements after "we can". If translators ignore the omitted elements, target audiences may not understand the meaning of the sentence. So translators should complete the sentence.

\section{Reduction}

According to the features of the subtitle translation, the subtitle should be short and simple, so the translators should adopt reduction strategy.

Example (5) I was wondering if I could speak to you for a minute. 能否借一步说话?

If we translate the sentence into “我想我可不可以跟你说一分钟呢? ”, which would be too long for target audiences to catch all the information in a short time. So the translator translates it into “能否借一步说话”, which is simple, clear, and in accordance with Chinese habits.

\section{Features of U.S. TV Drama Subtitle Translation}

The subtitle translation is not only an easy method to understand different cultures, but an important way to spread our own cultures. TV drama is a special work made according to maker's life experience, so it reflects the specific socio-culture background and has its own special characteristics.

\section{Instantaneity and Synchronism in Form}

The subtitle translation should synchronize with the original sound. So the features of subtitle translation must be in accord with the features of subtitle in form.

Instantaneity of subtitle claims that the subtitle translation should be brief, plain, and clear, which makes audiences familiar to it.

Example (6) Stefan: Stop it, Katherine.

别假装了。

Katherine: Stop what?

装什么? 
Synchronism of subtitle expects the subtitle translation keep the proper length. The subtitles should represent with the sounds and the pictures at the same time, or it will cause confusion and misunderstanding.

Example (7) Elena: Stefan's gone, I don't mean geographically. Stefan离开了, 心也不在了。

Actually, if the sentence is translated completely, it must be “Stefan走了, 我并不是说, 他只是仅仅离开 了这个地方, 更重要的是他的心也不在了”. But if we translate it into the second one, the subtitle translation will be too long compared with the source sentence, which will influence the pace of audience watching the program.

\section{Popularity and Localism in Content}

We know that the subtitles cannot stay at the screen for a long time, so audiences just have a short time to figure out the meaning of subtitles. Thus, the subtitles should be popular and easy to understand.

Example (8) Katherine: Tell Damon and Stefan that I want the moonstone, or I will rip this town apart until it rains blood.

\section{告诉Damon和Stefan, 我要月光石, 不然我将血洗本镇。}

“血洗” can not only convey the accurate information of the sentences, but also fit the way common audiences speak. Therefore, subtitle translation should be in accordance with Chinese expression.

The subtitle translated from other culture should not only send all the information, but also reflect the characteristics of the local culture. So the target language and the source language should be fused together in order to make the subtitle translation share more regional features. Therefore, localism makes the subtitle translation look so deep into the human mind.

Example (9) Damon, tell me you're actually gonna be careful for once.

Damon, 小心驶得万年船。

\section{Language Differences and Cultural Differences}

Subtitle translation is a new field of translation. The subject of subtitle translation is film and TV series. The film and TV series can entertain audiences, disseminate culture, and communicate civilization as well. But they are constrained by some factors. Thus, to translate the subtitles well, we should figure out these constrains.

Different language has different metrical structure. So the target language may have different rhythm from the source language. Sometimes it is funny to speak something in English, but when the sentence is translated to Chinese, it may lose the sense of humor. It is determined by language difference.

Every TV series may reflect the differential cultural background of a period of time or a group of people. So the TV series bear a heavy load of culture, including values, religious belief, and customs. According to Nida's theory and intercultural translation, the cultural elements can be divided into five parts: ecological cultural factors, material cultural factors, social-cultural factors, religious culture factors, and language culture factors. Language cultural factors reflect the variety of language. So it is very important to translate the subtitle into another language which makes the target audiences have the same feeling as the native audiences.

\section{Conclusion}

To sum up, this article studies subtitle translation from the perspective of Skopos Theory, with the subtitles 
of The Vampire Diaries as a case study. Chinese audiences could watch the U.S. TV series with better subtitle translation resources. Meanwhile, the Skopos Theory gives the subtitle translators a related reference theory when translating subtitles and makes a significant contribution to Chinese subtitle translation field.

However, the article is still far from satisfactory in the following two aspects: (1) the subtitle translations from the Vampire Diaries are chosen by author, which may not be comprehensive and (2) the author just discusses the subtitle translation from English to Chinese. However, there are thousands of languages in the world.

\section{References}

Gottlieb, H. (2004). Subtitles and international anglification. Nordic Journal of English Studies, 3, 219-230.

Nord, C. (2001). Translating as a purposeful activity: Functionalist approaches explained. Shanghai: Shanghai Foreign Language Education Press.

Shuttleworth, M., \& Cowie, M. (2004). Dictionary of translational studies. Shanghai: Shanghai Foreign Language Education Press. Vermeer, H. J. (1987). What does it mean to translate. Indian Journal of Applied Linguistics, 13(2), 25-33.

Vermeer, H. J. (1989). Skopos and commission in translational action. In A. Chesterman (Ed.), Reading in translation (pp. 173-187). New York: Routledge. 